\title{
Prognostic value of serum IL-8 and IL-10 in patients with ovarian cancer undergoing chemotherapy
}

\author{
LIXIA ZHANG $^{1 *}$, WEIWEI LIU ${ }^{1 *}$, XINBO WANG $^{2}$, XIAOLI WANG ${ }^{1}$ and HONG SUN ${ }^{1}$ \\ ${ }^{1}$ Department of Gynaecology, Yidu Central Hospital of Weifang, Weifang, \\ Shandong 262500; ${ }^{2}$ Department of Gynaecology, Affiliated Hospital of \\ Weifang Medical University, Weifang, Shandong 261031, P.R. China
}

Received May 23, 2018; Accepted November 27, 2018

DOI: $10.3892 / 01.2018 .9842$

\begin{abstract}
Prognostic value of serum interleukin-8 (IL-8) and interleukin-10 (IL-10) in patients with ovarian cancer undergoing chemotherapy was evaluated. The clinical data of ovarian tumor patients in Yidu Central Hospital of Weifang treated from January 2012 to December 2014 was retrospectively analyzed, 92 cases of which were malignant group, 64 cases were benign group, and 58 healthy subjects were selected as control group. Serum expression levels of IL-8 and IL-10 of the three groups were detected by enzyme-linked immunosorbent assay. Serum expression levels of IL-8 and IL-10 in benign and malignant groups both were higher than those in healthy control group $(\mathrm{P}<0.001)$. Serum expression levels of IL-8 and IL-10 of patients with ovarian cancer at III+IV stage were higher than that at I+II stage $(\mathrm{P}<0.001)$. Serum expression levels of IL-8 and IL-10 of patients with malignant ovarian tumors before chemotherapy were higher than those after chemotherapy $(\mathrm{P}<0.001)$. Serum levels of IL-8 and IL-10 of patients with malignant ovarian tumors in stable condition after chemotherapy were lower than those with recurrence and metastasis after chemotherapy $(\mathrm{P}<0.001)$. The median of serum expression levels of IL-8 and IL-10 was divided into low expression group and high expression group. The survival time of patients in high serum IL-8 and IL-10 expression group was significantly shorter than that in serum IL-8 and IL-10 low expression group $(\mathrm{P}<0.05)$. The survival time was negatively correlated with the expression levels of IL-8 and IL-10. Serum expression levels of IL-8 and IL-10 are closely related to the stages and prognosis of ovarian cancer. IL-8 and IL-10 may be involved in the occurrence and
\end{abstract}

Correspondence to: Dr Xinbo Wang, Department of Gynaecology, Affiliated Hospital of Weifang Medical University, 2428 Yuhe Road, Weifang, Shandong 261031, P.R. China

E-mail: xqb9ew@163.com

*Contributed equally

Key words: ovarian cancer, IL-8, IL-10, prognosis evaluation, survival analysis development of ovarian cancer. There are certain reference values on the changes of IL-8 and IL-10 levels, which may reflect the biological behavior and prognosis of ovarian cancer.

\section{Introduction}

Ovarian cancer has the highest mortality rate in gynecological malignancies at present (1). Due to the lack of typical clinical symptoms and occult onset at early stage, most patients with ovarian cancer have reached advanced stage by the time the diagnosis is confirmed, and even some have already metastasized (2). Clinically, ovarian cancer is mainly treated with cytoreductive surgery and adjuvant chemotherapy. However, for patients at advanced stage and with metastasis, even surgical treatment is difficult to stabilize the condition, and it easily relapse and metastasize $(3,4)$. It shows that improving the early diagnosis rate of ovarian cancer, as early as possible to find the invasion and metastasis of cancer cells and to take measures have important significance. Although the mechanism of the disease is not yet fully understood, the research regarding this respect has been the focus of medical workers around the world (5).

Considerable research shows that the abnormal expression of cytokines plays a key role in the occurrence and development of ovarian cancer, which may be due to the expression imbalance of varieties of cytokines (6-8). Cytokines promote or inhibit the tumor cell differentiation through different secretory ways, thereby affect the angiogenesis and nutrient supply of the tumor, and regulate the immune response of tumor cells to affect their clinical treatment (9). Ovarian tumors are associated with many cytokines such as interleukin-8 (IL-8) and IL-10, and their abnormal expression affects the overall process of occurrence, development and metastasis of ovarian cancer. IL- 8 is a cytokine which can accelerate cancer cells metastasis. IL-10 is a cytokine that can reduce and change the immune activity of the body (10). It has been reported that the expressions of IL-8 and IL-10 is enhanced in ovarian cancer patients, and the abnormal expression of these two cytokines is accompanied throughout the course of the disease (11).

The purpose of this investigation was to analyze the relationship between the expressions of IL-8 and IL-10 and patients with ovarian cancer undergoing chemotherapy, and to provide methods and references for early diagnosis, disease 
evaluation and treatment of ovarian cancer, which has certain clinical significance.

\section{Materials and methods}

General information. The clinical data of 156 patients with pathologically confirmed ovarian tumors who were treated at the Yidu Central Hospital of Weifang (Weifang, China) from January 2012 to December 2014 was retrospectively analyzed. The average age was $50.84 \pm 13.82$ years, including 92 cases in malignant group and 64 cases in benign group, with 58 healthy subjects as control group, and the average age was $51.05 \pm 12.74$ years. No significant differences were found between the two groups $(\mathrm{P}>0.05)$. None of the subjects were treated with endocrine therapy, biological therapy, chemical therapy and radiation therapy before operation, including 20 cases at stage I and II, and 72 cases at stage III and IV. Patients with ovarian epithelial tumor all received platinumbased chemotherapy after admission and were followed up for 36 months. None of the subjects had taken immunomodulators or hormone drugs in the past six months.

The study was approved by the Ethics Committee of Yidu Central Hospital of Weifang. Signed informed consents were obtained from the patients or the guardians. General information of the patients is shown in Table I.

Reagents and instruments. ELISA kit was purchased from Shanghai Xinran Biotechnology Co., Ltd. (Shanghai, China), and Antus PHOMO automatic microplate reader was purchased from Bio-Rad Laboratories, Inc., (Hercules, CA, USA).

Detection of serum $I L-8$ and $I L-10$. Peripheral venous blood ( $3 \mathrm{ml}$ ) was taken from study subjects following fasting in the morning as the first serum sample. The second serum sample was taken from the patients treated with chemotherapy on the second morning after the end of second stage, and was centrifuged at $2,600 \mathrm{x}$ g for $8 \mathrm{~min}$ at $22^{\circ} \mathrm{C}$. Serum IL-8, IL-10 and OD values at the wavelength of $450 \mathrm{~nm}$ were measured by ELISA method. The operation was carried out strictly according to the instructions.

Statistical analysis. The statistical software SPSS 19.0 (IBM Corp., Armonk, NY, USA) was used to carry out the analysis. The t-test was applied in data measurement, and the comparison was made before and after treatment with the paired t-test. The comparison among groups was performed with One-way ANOVA analysis, and least significant difference test, and Kaplan-Meier survival curves and the log-rank test was used to draw survival curve in survival analysis. $\mathrm{P}<0.05$ was considered to indicate a statistically significant difference.

\section{Results}

Comparison of serum levels of IL-8 and IL-10 among the three groups of patients. The expression level of serum IL-8 was $79.68 \pm 9.53 \mathrm{ng} / \mathrm{l}$ in benign group and $220.54 \pm 12.49 \mathrm{ng} / \mathrm{l}$ in malignant group, and both were higher than the $54.31 \pm 10.26 \mathrm{ng} / 1$ in healthy control group. The expression level of IL-10 was $7.05 \pm 2.37 \mathrm{ng} / \mathrm{l}$ in benign group and
Table I. General information.

\begin{tabular}{|c|c|c|c|}
\hline \multirow[b]{2}{*}{ Factors } & \multicolumn{3}{|c|}{$\mathrm{n}(\%)$} \\
\hline & $\begin{array}{l}\text { Malignant } \\
\text { group } \\
(\mathrm{n}=92)\end{array}$ & $\begin{array}{l}\text { Benign } \\
\text { group } \\
(n=64)\end{array}$ & $\begin{array}{l}\text { Control } \\
\text { group } \\
(\mathrm{n}=58)\end{array}$ \\
\hline \multicolumn{4}{|l|}{ Age (years) } \\
\hline$\geq 50$ & $48(52.17)$ & $34(53.13)$ & $30(51.72)$ \\
\hline$<50$ & $44(47.83)$ & $30(46.87)$ & $28(48.28)$ \\
\hline \multicolumn{4}{|l|}{ Tissue types } \\
\hline Serous tumor & & $27(29.35)$ & \\
\hline Mucinous tumor & & $46(50.00)$ & \\
\hline Endometrioid tumors & & $19(20.65)$ & \\
\hline \multicolumn{4}{|l|}{ Tumor stages } \\
\hline $\mathrm{I}+\mathrm{II}$ & & $20(21.74)$ & \\
\hline III+IV & & $72(78.26)$ & \\
\hline \multicolumn{4}{|l|}{ Lymphatic metastasis } \\
\hline Yes & & $52(56.52)$ & \\
\hline No & & $40(43.48)$ & \\
\hline \multicolumn{4}{|l|}{ Distant metastasis } \\
\hline Yes & & $43(46.74)$ & \\
\hline No & & $49(53.26)$ & \\
\hline \multicolumn{4}{|l|}{ Tumor size } \\
\hline$<4 \mathrm{~cm}$ & & $35(38.04)$ & \\
\hline$\geq 4 \mathrm{~cm}$ & & $57(61.96)$ & \\
\hline \multicolumn{4}{|l|}{ Differentiation degree } \\
\hline Middle and low & & $42(45.65)$ & \\
\hline High & & $50(54.35)$ & \\
\hline
\end{tabular}

$17.35 \pm 4.02 \mathrm{ng} / \mathrm{l}$ in malignant group, and both were higher than the $3.81 \pm 0.52 \mathrm{ng} / 1$ in healthy control group. Serum expression levels of IL-8 and IL-10 in benign and malignant groups both were higher than those in healthy controls. The levels of IL-8 and IL-10 in malignant group were statistically significant higher than those in benign group $(\mathrm{P}<0.001)$ (Table II).

Comparison of serum IL-8 and IL-10 levels of patients with malignant ovarian tumors at clinical stages. The IL-8 level of ovarian cancer I+II was $181.37 \pm 13.54 \mathrm{ng} / \mathrm{l}$, and the level of IL-10 was $13.52 \pm 2.16 \mathrm{ng} / \mathrm{l}$. The IL-8 level of ovarian cancer III+IV was $228.41 \pm 6.79 \mathrm{ng} / \mathrm{l}$, and the level of IL-10 was $20.16 \pm 4.84 \mathrm{ng} / \mathrm{l}$. The serum expression levels of IL-8 and IL-10 at ovarian cancer III+IV stage were higher than those at I+II stage $(\mathrm{P}<0.001)$ (Table III).

Changes of serum levels of IL-8 and IL-10 of malignant ovarian tumor patients before and after chemotherapy. Serum levels of IL-8 and IL-10 in malignant ovarian tumor patients were respectively $220.54 \pm 12.49$ and $17.35 \pm 4.02 \mathrm{ng} / 1$ before chemotherapy, and were respectively $159.82 \pm 8.77$ and $11.48 \pm 1.74 \mathrm{ng} / \mathrm{l}$ after chemotherapy. Serum levels of IL-8 and IL-10 of malignant ovarian tumor patients before chemotherapy both were statistically significant higher than those after chemotherapy $(\mathrm{P}<0.001)$ (Table IV). 
Table II. Comparison of IL-8 and IL-10 levels in serum of patients among the three groups (ng/l).

\begin{tabular}{lcccr}
\hline Items & Control group & Benign group & Malignant group & F-value \\
\hline Case number & 58 & 64 & 92 & P-value \\
IL-8 & $54.31 \pm 10.26$ & $79.68 \pm 9.53^{\mathrm{a}}$ & $220.54 \pm 12.49^{\mathrm{b}}$ & 50.970 \\
IL-10 & $3.81 \pm 0.52$ & $7.05 \pm 2.37^{\mathrm{a}}$ & $17.35 \pm 4.02^{\mathrm{b}}$ & 55.570 \\
\hline
\end{tabular}

${ }^{\mathrm{a}} \mathrm{P}<0.001$ vs. control group, ${ }^{\mathrm{b}} \mathrm{P}<0.001$ vs. control group. IL-8, interleukin- 8 .

Table III. Comparison of IL-8 and IL-10 levels in serum of malignant ovarian tumor patients at different clinical stages (ng/l).

\begin{tabular}{lccc}
\hline Clinical stages & Case number & IL-8 & IL-10 \\
\hline I+II & 20 & $181.37 \pm 13.54$ & $13.52 \pm 2.16$ \\
III+IV & 72 & $228.41 \pm 6.79$ & $20.16 \pm 4.84$ \\
t value & & 21.620 & 8.308 \\
P-value & & $<0.001$ & $<0.001$ \\
\hline
\end{tabular}

IL-8, interleukin-8.

Table IV. Changes of IL- 8 and IL-10 levels in serum of malignant ovarian tumor patients before and after chemotherapy (ng/l).

\begin{tabular}{lccc}
\hline Groups & Case number & IL-8 & IL-10 \\
\hline $\begin{array}{l}\text { Before } \\
\text { chemotherapy }\end{array}$ & 92 & $220.54 \pm 12.49$ & $17.35 \pm 4.02$ \\
$\begin{array}{l}\text { After } \\
\text { chemotherapy }\end{array}$ & 92 & $159.82 \pm 8.77$ & $11.48 \pm 1.74$ \\
t value & & 38.16 & 12.85 \\
P-value & & $<0.001$ & $<0.001$ \\
\hline
\end{tabular}

IL-8, interleukin-8.

Changes of serum levels of IL-8 and IL-10 of malignant ovarian tumor patients before and after chemotherapy. Serum levels of IL- 8 and IL-10 were, respectively 184.52 \pm 11.47 and $18.24 \pm 3.05 \mathrm{ng} / 1$ in malignant ovarian tumor patients with recurrence and metastasis after chemotherapy, and serum levels of IL- 8 and IL-10 were, respectively $151.08 \pm 9.38$ and $9.46 \pm 1.08 \mathrm{ng} / \mathrm{l}$ in malignant ovarian tumor patients in stable condition after chemotherapy. The serum levels of IL-8 and IL-10 in malignant ovarian tumor patients in stable condition after chemotherapy both were statistically significant lower than those in malignant ovarian tumor patients with recurrence and metastasis after chemotherapy $(\mathrm{P}<0.001)($ Table $\mathrm{V})$.

The median of serum expression level of IL-8 of ovarian cancer patients after chemotherapy was $167.43 \mathrm{ng} / \mathrm{l}$ and 46 were in the low expression and the high expression group, respectively. The median of serum expression level of IL-10 of ovarian cancer patients after chemotherapy was $13.54 \mathrm{ng} / \mathrm{l}$ and 46 were in the low expression group and the high
Table V. Comparison of IL-8 and IL-10 levels in serum of malignant ovarian tumor patients with stable state or recurrent and metastasis after chemotherapy (ng/l).

\begin{tabular}{lccc}
\hline Groups & Case number & IL-8 & IL-10 \\
\hline $\begin{array}{l}\text { Recurrence and } \\
\text { metastasis }\end{array}$ & 59 & $184.52 \pm 11.47$ & $18.24 \pm 3.05$ \\
$\begin{array}{l}\text { after chemotherapy } \\
\begin{array}{l}\text { Stable condition } \\
\text { after chemotherapy }\end{array}\end{array}$ & 33 & $151.08 \pm 9.38$ & $9.46 \pm 1.08$ \\
t value & & 11.16 & 14.81 \\
P-value & $<0.001$ & $<0.001$ \\
\hline
\end{tabular}

IL-8, interleukin-8.

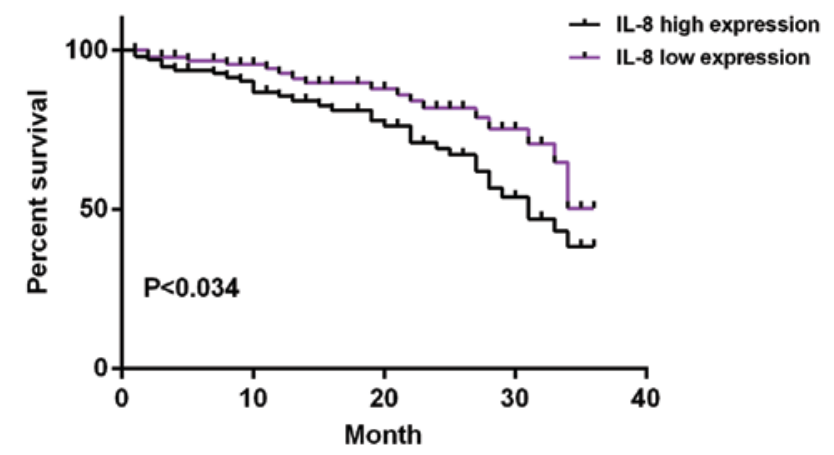

Figure 1. Relationship between IL-8 and survival of ovarian cancer patients after chemotherapy. Kaplan-Meier survival curve showed that the survival time of patients with high expression of IL-8 was significantly shorter than that with low expression of IL-8 $(\mathrm{P}<0.034)$. IL-8, interleukin-8.

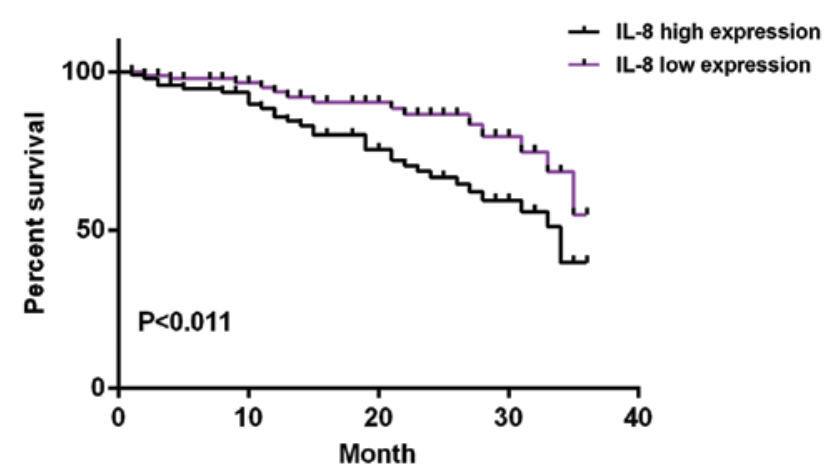

Figure 2. Relationship between IL-10 and survival of ovarian cancer patients after chemotherapy. Kaplan-Meier survival curve showed that the survival time of patients with high expression of IL-10 was significantly shorter than that with low expression of IL-10 $(\mathrm{P}<0.011)$. IL-10, interleukin-10. 
expression group, respectively. The average survival time of IL-8 low expression group was $33.12 \pm 1.08$ months and that of IL-8 high expression group was $28.82 \pm 2.84$ months. The average survival time of IL-10 low expression group was $32.16 \pm 1.88$ months and that of IL-10 high expression group was $29.86 \pm 2.02$ months. Survival analysis showed that the survival time of patients with high expression of IL- 8 and IL-10 was significantly shorter than that of patients with low expression of IL-8 and IL-10 $(\mathrm{P}<0.05)$ (Figs. 1 and 2).

\section{Discussion}

The pathogenesis of ovarian cancer is not yet clear and there is a lack of appropriate and accurate early diagnosis. Therefore, the 5-year survival rate of ovarian cancer does not exceed $30 \%$ (12). According to statistics, $>120,000$ people worldwide die of this disease every year (13). The process of cancer cell growth and diffusion is extremely complex, and the possible influencing factors are various, but mainly tumor angiogenesis (14). IL-8 can accelerate tumor angiogenesis and promote the progress of ovarian cancer. It has been widely accepted that IL-8 plays an important role in tumor angiogenesis (15). When a person is healthy and in good condition, the IL-10 content in the body is extremely low, but if someone is sick or stimulated by external environmental factors, such as pregnancy, tumor and infectious disease the IL-10 content will increase rapidly, and it only affects the human body. The reason is that there is no homologous sequence in other organism cells (16).

This study shows that serum expression levels of IL- 8 and IL-10 in benign ovarian disease group and malignant ovarian tumor group both were statistically significantly higher than those in healthy control group $(\mathrm{P}<0.001)$. The serum expression levels of IL-8 and IL-10 at ovarian cancer III+IV stage were statistically significantly higher than those at ovarian cancer I+II stage $(\mathrm{P}<0.001)$. The results of Charbonneau et al (11) are consistent with ours. The expression of IL-8 and IL-10 in ovarian cancer was positively correlated with clinical stages, and the occurrence and development of ovarian cancer was closely related to IL- 8 which is a special marker (17). The high expression of IL-10 in tumor microenvironment inactivate the cell lesion, however, tumor cells cannot be effectively eliminated. Therefore, the measurement of IL-8 and IL-10 levels has an important reference value in judging the malignant degree and staging of ovarian cancer (17-19). Serum levels of IL-8 and IL-10 in malignant ovarian tumor patients before chemotherapy both were statistically significant higher than those after chemotherapy $(\mathrm{P}<0.001)$. Serum levels of IL-8 and IL-10 of malignant ovarian tumor patients in stable condition after chemotherapy were statistically significantly lower than those in patients with recurrence and metastasis after chemotherapy $(\mathrm{P}<0.001)$. Our results are similar to those of Matte et al (20). Studies show that polyphenols can enhance the sensitivity of ovarian cancer cell CAOV-3 to cisplatin. The cells produce high levels of IL-8, IL-10, and have poor sensitivity to cisplatin. Polyphenols can inhibit CAOV-3 cells to produce IL-8 and IL-10. Therefore, the patients with metastasis and recurrence after chemotherapy may be due to the high levels of IL-8 and IL-10 in vivo reducing the sensitivity of cancer cells to chemotherapy, thus leading to recurrence and metastasis. The average survival time of IL-8 in low expression group was $33.12 \pm 1.08$ months, and that of IL-8 in high expression group was $28.82 \pm 2.84$ months. The average survival time of IL-10 in low expression group was $32.16 \pm 1.88$ months and that of IL-10 in high expression group was $29.86 \pm 2.02$ months. Survival analysis showed that the survival time of patients with high expression of IL-8 and IL-10 was significantly shorter than that of patients with low expression of IL-8 and IL-10 (log-rank, $\mathrm{P}<0.05)$. The results of follow-up were consistent with the results of Table V. Serum expression of IL- 8 and IL-10 in patients with poor chemotherapy effect and those in deceased patients were higher, which indicated that the expressions of IL-8 and IL-10 played a certain role in predicting and evaluating the survival prognosis of ovarian cancer patients after chemotherapy.

However, the study has some limitations. Although the follow-up results of ovarian cancer patients after chemotherapy are consistent with the results of our study, which shows that the high expression of IL-8 and IL-10 can shorten the survival time of patients. Nevertheless, there may be still other factors which need to be further studied.

In conclusion, serum high expression of IL-8 and IL-10 is involved in the occurrence and development of ovarian cancer, and also have an effect on sensitivity to chemotherapy. The changes of IL- 8 and IL-10 levels indirectly reflect the biological behavior and prognosis of ovarian cancer, which has certain clinical significance.

\section{Acknowledgements}

Not applicable.

\section{Funding}

No funding was received.

\section{Availability of data and materials}

The datasets used and/or analyzed during the present study are available from the corresponding author on reasonable request.

\section{Authors' contributions}

LZ drafted the manuscript. LZ and WL were mainly devoted to collecting and interpreting the general data. XinboW and XiaoliW performed ELISA. LZ and HS were responsible for statistical analysis. All authors read and approved the final study.

\section{Ethics approval and consent to participate}

The study was approved by the Ethics Committee of Yidu Central Hospital of Weifang (Weifang, China). Signed informed consents were obtained from the patients or the guardians.

\section{Patient consent for publication}

Not applicable.

\section{Competing interests}

The authors declare that they have no competing interests. 


\section{References}

1. Zhao BB, Yang ZJ, Wang Q, Pan ZM, Zhang W and Li L: Clinical validation of multiple biomarkers suspension array technology for ovarian cancer. Zhonghua Fu Chan Ke Za Zhi 52: 11-19, 2017 (In Chinese)

2. Hennessy BT, Coleman RL and Markman M: Ovarian cancer. Lancet 374: 1371-1382, 2009.

3. Dubosq F, Ploussard G, Soliman H, Turpin E, Latil A, Desgrandchamps F, de The $\mathrm{H}$ and Mongiat-Artus P: Identification of a three-gene expression signature of early recurrence in non-muscle-invasive urothelial cell carcinoma of the bladder. Urol Oncol 30: 833-840, 2012.

4. Cho KR and Shih IeM: Ovarian cancer. Annu Rev Pathol 4 : 287-313, 2009.

5. Holschneider $\mathrm{CH}$ and Berek JS: Ovarian cancer: Epidemiology, biology, and prognostic factors. Semin Surg Oncol 19: 3-10, 2000.

6. Gorelik E, Landsittel DP, Marrangoni AM, Modugno F, Velikokhatnaya L, Winans MT, Bigbee WL, Herberman RB and Lokshin AE: Multiplexed immunobead-based cytokine profiling for early detection of ovarian cancer. Cancer Epidemiol Biomarkers Prev 14: 981-987, 2005.

7. Mazzucchelli I, Avanzini MA, Ciardelli L, Pagani S, Greco R, Belloni C, Castellazzi A, Marconi M, Rondini G and Polatti F: Human amniotic fluid cells are able to produce IL-6 and IL-8. Am J Reprod Immunol 51: 198-203, 2004.

8. Gorelik E, Landsittel DP, Marrangoni AM, Modugno F, Velikokhatnaya L, Winans MT, Bigbee WL, Herberman RB and Lokshin AE: Multiplexed immunobead-based cytokine profiling for early detection of ovarian cancer. Cancer Epidemiol Biomarkers Prev 14: 981-987, 2005.

9. Duan ZG and Yang WM: Analysis of cytokines (IL-2, IL-8, IL-10) in the expressed prostatic secretions of chronic prostatitis. Zhonghua Nan Ke Xue 11: 201-203, 2005 (In Chinese).

10. Redford PS, Murray PJ and O'Garra A: The role of IL-10 in immune regulation during $M$. tuberculosis infection. Mucosal Immunol 4: 261-270, 2011.

11. Charbonneau B, Goode EL, Kalli KR, Knutson KL and Derycke MS: The immune system in the pathogenesis of ovarian cancer. Crit Rev Immunol 33: 137-164, 2013.
12. Block MS, Maurer MJ, Goergen K, Kalli KR, Erskine CL, Behrens MD, Oberg AL and Knutson KL: Plasma immune analytes in patients with epithelial ovarian cancer. Cytokine 73 : 108-113, 2015.

13. Vergote I, Rustin GJ, Eisenhauer EA, Kristensen GB, Pujade-Lauraine E, Parmar MK, Friedlander M, Jakobsen A and Vermorken JB: Re: New guidelines to evaluate the response to treatment in solid tumors [ovarian cancer]. Gynecologic Cancer Intergroup. J Natl Cancer Inst 92: 1534-1535, 2000.

14. Xiong W, Cao LL, Jiang LP, Xia H and Liang ZQ: Clinical comparative analysis of comprehensive laparoscopic and laparotomic staging of early-stage epithelial ovarian cancer. Zhonghua Fu Chan Ke Za Zhi 52: 103-109, 2017 (In Chinese).

15. Lokshin AE, Winans M, Landsittel D, Marrangoni AM, Velikokhatnaya L, Modugno F, Nolen BM and Gorelik E: Circulating IL-8 and anti-IL-8 autoantibody in patients with ovarian cancer. Gynecol Oncol 102: 244-251, 2006.

16. O'Keefe GM, Nguyen VT and Benveniste EN: Class II transactivator and class II MHC gene expression in microglia: Modulation by the cytokines TGF-beta, IL-4, IL-13 and IL-10. Eur J Immunol 29: 1275-1285, 1999.

17. Lane D, Matte I, Rancourt C and Piché A: Prognostic significance of IL-6 and IL-8 ascites levels in ovarian cancer patients. BMC Cancer 11: 210-210, 2011.

18. Zhang T, Ma Z, Wang R, Wang Y, Wang S, Cheng Z, Xu H, Jin $\mathrm{X}, \mathrm{Li} \mathrm{W}$ and Wang $\mathrm{X}$ : Thrombin facilitates invasion of ovarian cancer along peritoneum by inducing monocyte differentiation toward tumor-associated macrophage-like cells. Cancer Immunol Immunother 59: 1097-1108, 2010.

19. Nishio H, Yaguchi T, Sugiyama J, Sumimoto H, Umezawa K, Iwata T, Susumu N, Fujii T, Kawamura N, Kobayashi A, et al: Immunosuppression through constitutively activated NF- $\kappa B$ signalling in human ovarian cancer and its reversal by an NF- $\kappa \mathrm{B}$ inhibitor. Br J Cancer 110: 2965-2974, 2014.

20. Matte I, Lane D, Laplante C, Rancourt C and Piché A: Profiling of cytokines in human epithelial ovarian cancer ascites. Am J Cancer Res 2: 566-580, 2012.

(i) $($ This work is licensed under a Creative Commons Attribution-NonCommercial-NoDerivatives 4.0 International (CC BY-NC-ND 4.0) License. 